\title{
LA-ICP-MS/MS geological applications from volcanic halogens to the Mars2020 mission.
}

\author{
BENOIT CARON $^{1}$, BENOIT DUBACQ ${ }^{1}$, BENOIT \\ VILLEMANT $^{1}$, SARAH FIGOWY ${ }^{2}$, GIULIA DEL MANZO ${ }^{3}$, \\ THOMAS GYOMLAI ${ }^{4}$, AGNES COUSIN ${ }^{5}$, PHILIPPE \\ AGARD $^{1}$, ANNE LE FRIANT ${ }^{3}$ AND MR. THOMAS ZACK ${ }^{6}$ \\ ${ }^{1}$ Sorbonne Université \\ ${ }^{2}$ Institut des Sciences de la Terre de Paris, ISTeP UMR 7193, \\ Sorbonne Université \\ ${ }^{3}$ Université de Paris \\ ${ }^{4}$ Sorbonne université \\ ${ }^{5}$ IRAP (Institut de Recherche en Astrophysique et Planétologie), \\ CNRS \\ ${ }^{6}$ Department of Earth Sciences, University of Gothenburg \\ Presenting Author: benoit.caron@sorbonne-universite.fr
}

The facilities of the ALIPP6 geochemical analytical laboratory are used for several geological applications, from halogens to Mars2020 targets calibrations and to $\mathrm{Rb}-\mathrm{Sr}$ datings.

The recent developments of the ICP-MS/MS (Agilent 8800 and 8900) technique coupled with a laser ablation (Photon Machine Excimer $193 \mathrm{~nm}$ ) allows in situ analysis of most of elements of the Mendeleev's periodic table. The LA-ICP-MS/MS technique has many advantages compared to the classical LAICP-MS for analyzing trace elements in geological material, as it can resolve many important isobaric interferences.

Dry plasma as produced by laser ablation already strongly reduces isobaric interferences related to production of oxides and double charged ions. The MS/MS mode with no gas in the reaction cell, compared to single quadrupole mode (MS), strongly improves the mass resolution, reduces the polyatomic interferences and increases peak/background ratios of many elements due to the double $\mathrm{M} / \mathrm{Z}$ selection.

The use of collision or reaction gases (e.g. $\mathrm{He}, \mathrm{H}, \mathrm{N}_{2} \mathrm{O}$ ) in the reaction cell bracketed by the two quadrupoles, allows the successful selective suppression of interfering species through selective reactions. In addition, reaction or collision gas in the cell, focuses the ion flow and improves the signal intensity.

Chlorine $(\mathrm{Cl})$, bromine $(\mathrm{Br})$ and iodine (I) are directly measured in minerals or glasses (residual glass or melt inclusions) of natural systems, with beam sizes as low as $20 \mu \mathrm{m}$. LA-ICP-MS/MS using both no gas and gas reaction modes may become the reference method for in-situ analysis of $\mathrm{Cl}, \mathrm{Br}$ and $\mathrm{I}$ and many other volatile elements in magmatic rocks and most geological material.

LA-ICP-MS/MS with oxyde reaction gaz, is also used to obtain Rb-Sr ages, as developed by Zack and Holgman (2016). Comparison between $\mathrm{O}_{2}$ and $\mathrm{N}_{2} \mathrm{O}$ shows a marked difference of separation capacity of ${ }^{87} \mathrm{Rb}$ and ${ }^{87} \mathrm{Sr}$.

ALIPP6 has been involved in the MARS 2020 program with the SuperCam instrument of Perseverance Rover and LA-ICPMS/MS allows the calibrations of Flight model of the calibration targets, that are now on-board. 